\title{
Isolation of Soil Bacteria for Potential Production of Antibiotics and their Inhibitory Effect on Growth of Pathogens
}

\author{
Vijaykumar Biradar ${ }^{1 *}$, S. Ashwini, Pooja Lachuriye ${ }^{2}$, Sadia Fatima ${ }^{2}$ and Awase Syed ${ }^{2}$ \\ ${ }^{1}$ HOD \& Director, PG Studies \& Research Centre in Biotechnology, Karnatak College, \\ Bidar-585 401, Karnataka, India \\ ${ }^{2}$ Research scholars, Department of Biotechnology, Karnatak College, Bidar-584 401, \\ Karnataka, India \\ *Corresponding author
}

\section{A B S T R A C T}

Keywords

Soil Bacteria, Antibiotics

P. aeruginosa,

E. coli,

E. faecalis.

\section{Article Info}

Accepted:

23 July 2016

Available Online:

10 August 2016
Soil is a richest source of microorganisms. These have played a significant role in antibiotic discovery. Though, thousands of antibiotics were discovered from soil microorganisms, very few were potent or old antibiotics loss their potency or few pathogens became multiple drug resistance. To solve these problems one has to discover new antibiotics to control pathogens. Hence, selective isolation of rare microorganisms from soil may allow the discovery of new antibiotics. Therefore they were isolated and screened for antibiotic production $\&$ to find their inhibitory effects on pathogens. It was observed that, two colonies (C2 \& C4) of seven antibiotic producing bacterial colonies were identified as $P$. aeruginosa strain$1(\mathrm{C} 2)$ \& strain-2(C4), and remaining unknown colonies were named as $\mathrm{C} 1, \mathrm{C} 3$, C5, C6 \& C7. Out of seven bacteria isolated, antibiotics of $\mathrm{C} 1$ has inhibition effect on growth of E. coli; C2 on E. coli, P. aeruginosa \& S. aureus; C3 \& C5 on S. aureus; C4, C6 \& C7 on E . faecalis, Further, each of soil bacteria antibiotics shown varied degree of antibiotic effects on different pathogens. $\mathrm{C} 4$ has highest inhibitory effect of the growth of E. faecalis; followed by C5 on S. aureus and C2 on $P$. aeruginosa. The antibiotic effect of some selected soil bacteria, and commercial streptomycin antibiotic has almost equivalent affect on four studied pathogens.

\section{Introduction}

Bacteria found in soils can be bacilli, cocci and spirilla. Bacilli are more numerous than others in the soil and are widely distributed (Brock et al., 1991). Many antibiotics are known to exist in nature, but still efforts to discover new antibiotics are continued. In fact bacillus species have produced antibiotics in soluble form and these antibiotics have been found to be cheaper and more effective, hence these microorganisms are preferable for commercial production (Sandhya et al., 2015). The significance of these is mainly in the biotransformation of various raw materials into compost \& bioremediation, however their intensive applications in 
clinical practices like virulence, production of antibiotics, resistance etc., are still need to be studied.

Pseudomonas aeruginosa is a common gram negative bacillus bacterium that can cause disease in plants and animals, including humans. It is a prototypical "Multidrug resistant (MDR) pathogen" recognized for its ubiquity, its intrinsic advanced antibiotic resistance mechanisms, and its association with serious illnesses such as ventilatorassociated pneumonia and various sepsis syndromes. $P$. aeruginosa is not extremely virulent in comparison with other major pathogenic bacteria Sps such as Staphylococcus aureus and streptococcus pyogenes. Further, among various strains, some are pathogenic, some are antibiotic resistant \& some are free living saprophytic bacteria.

$P$. aeruginosa is the quintessential opportunistic pathogen of humans that can invade virtually any tissue. The most virulent Pseudomonas species produce mucoid colonies and green pigments (Fig.1a $\& b)$.

\section{Antibiotics}

Antibiotics are medicines that kill bacteria or slow the growth of bacteria. They are used to cure diseases. Antibiotics are natural drugs that are produced by several fungi or bacteria. Over five thousand antibiotics have been identified from the culture of Gram positive, Gram negative and filamentous fungi but only hundred antibiotics have been commercially used to treat human, animal and plant disease. Therefore screening of new antibiotics is still needed. Further, certain pathogenic bacteria are multidrug \& antibiotic resistant. This problem can be solved only when new antibiotics are discovered. A major feature of industrial antibiotics production is directed to screening of new potent antibiotics producing organism either from natural sources or from established culture. Screening for antibiotics producing microorganism, can be detected and isolated by the use of highly selective procedure which allows detection and isolation of only those microorganism of interest from a large population is possible. Soil is the largest source of microorganism, \& majority of antibiotics so far isolated were produced from Streptomycetes, which are inhabitants of the soil (Srividya et al., 2008). Selective isolation of rare microorganisms may allow the discovery of new bioactive metabolites (Vineeta et al., 2009).

The problem of resistance against the present antibiotics in bacteria increases day by day. So here is an urgent need to search new antibiotics or the sources of new antibiotics. A lot of work has been done during last few decades, that has witnessed the production of novel antibiotics from different microorganisms. Soil is a primary source of microorganisms. Soil bacteria \& fungi have played a significant and an important role in antibiotic discovery. The numbers \& species of microbes in soil is depend on environmental conditions like nutrient availability, soil texture ,presence of moisture in soil and type of vegetation cover, and their number varies according to type of environmental condition (Atlas and Barhta,1998). From ancient times is well understood that, natural products have a key role in the discovery in development of many antibiotics (Newman and Cragg, 2007). One of the best approach to the discovery of new antimicrobial agents natural sources has been to use folklore or historical records to guide the collection of samples or a good research work on the soil of that area (Cordell et al, 1994). 
Antibiotics are one of the important pillars of modern medicines (Ball et al., 2004), but old antibiotics lose their efficiency and they are necessarily replaced with new ones for many species of pathogenic bacteria (Hancock, 2007). Microorganisms that are able to producing secondary metabolites have adverse chemical structure and biological activities and are produced only by some species of genus Bacillus (Stachelhaus et al., 1995). Therefore the present research study was carried out to survey on antibiotic producing bacteria from soil of Bidar district (Karnataka state, India) $\&$ to find their inhibitory effect on the growth \& reproduction of selected pathogens such as Staphylococcus aureus, Eschereschia.coli, Enterococcus faecalis and Pseudomonas aeruginosa.

\section{Materials and Methods}

\section{Soil sample collection}

Four different types of soil samples collected based on texture \& vegetation covered over the soil from different localities of Bidar such as i) Sacred groove of Papanash temple (forest soil), ii)Near pond of fort (Pond soil), iii) Near Sri Sai chemical Industry, Kolar (Industrial soil), and iv) Agriculture land of Janawada (Rhizosphere soil). They were used immediately for serial dilution $\&$ isolation of soil microbes (Fig.2).

\section{Collection of test organisms}

Fresh culture of pathogenic bacteria such as Eschereschia coli, Enterococcus feacalis, Pseudomonas aeruginosa \& Staphylococcus aureus were collected from Azyme Biosciences, Bangalore and sub cultured in nutrient broth for pure line growth.

\section{Preparation of culture plates}

Nutrient agar medium \& nutrient broth of $500 \mathrm{ml}$ each were prepared as per table 1 .
They were autoclaved, \& nutrient agar medium was poured into sterilized petridishes, and nutrient broth was poured into test tubes, and then allowed to cool.

\section{Serial dilution of soil samples \& inoculation}

Freshly collected each of soil samples was weighed $1 \mathrm{gm}$. Six test tubes were taken and each filled with $9 \mathrm{ml}$ of $0.9 \% \mathrm{NaCl}$ solution \& labeled serially such as $1,2,3,4$ etc. $1 \mathrm{gm}$ of soil was added into first test tube, shaken well \& allowed to settle the soil particles at bottom. $1 \mathrm{ml}$ of supernatant solution from first test tube was added into the second tube $\&$ shaken well. Similarly, $1 \mathrm{ml}$ from $2^{\text {nd }}$ tube added into the $3^{\text {rd }}$ tube $\&$ these steps repeated till $6^{\text {th }}$ tube to get serial dilutions of $1 / 10,1 / 100,1 / 1000,1 / 10000$, and 1/100000.

The soil sample from last test tube was pour plated on nutrient agar medium for microbial growth for 2 days \& number of bacterial colonies was observed \& each bacteria was selected based on colour, shape $\&$ texture of colony for pure line culture \& these unknown colonies named as $\mathrm{C} 1, \mathrm{C} 2$, C3, C4, C5, C6 \& C7 (Fig.3). Each selected colony was inoculated in to nutrient broth medium for mass-culture.

\section{Inoculation of test organisms (Pathogens)}

The test organisms such as Eschereschia coli, Enterococcus faecalis, Pseudomonas aeruginosa \& Staphylococcus aureus were separately inoculated by swabbing the microorganisms by sterilized cotton on to the culture medium to grow the microbes into lawns. Each of mass cultured pure line bacteria of soil was inoculated into the separate wells \& simultaneously, commercial streptomycin disc (as control) was used for comparative study. Culture plates were incubated at $37^{\circ} \mathrm{C}$ in the incubator for $24 \mathrm{hrs}$ to observe the results. 
Determination of Antibacterial effect of isolated soil bacteria

After 24hrs of incubation, culture plates were observed for clear inhibitory zone formation around each well (Fig.4). The rate of effect of isolated bacteria on each test organism was detected by measuring the diameter of each growth inhibition zone around well.

\section{Identification of antibiotics producing bacteria}

Out of seven colonies selected, two colonies were temporarily named as C2 (round, mucoid, creamy white, raised, smooth \& dull colony) \& C4 (creamy white,nonmucoid, cloudy, rough colony) based on color, texture (Sandhya et al., 2015) \& thier maximum effect on pathogens (E.coli, E. faecalis, S. aureus \& P. aeruginosa) and sent them for species idenification to Chromus Biotech, laboratory, Bengaluru (Karnataka). Remaining five colonies were named as such $\mathrm{C} 1$ (white, cloudy \& rough colony), C3 (orange, smooth \& shiny), C5 (Creamy white, cloudy \& smooth colony, C6 (white, cloudy \& rough colony) \& C7 (white, smooth \& shiny colony) (Fig.3).

\section{Detection of strains of isolated C2 \& C4 bacteria}

C2 \& C 4 bacteria were detected as P.aeruginosa strains $(1 \& 2)$ with the help of Chromus Biotech laboratory, B'luru. But their strain name is detected by following DATA BASE. Chart \& key points (5a, b, c $\& \mathrm{~d})$.

\section{Results and Discussion}

Various pathogens have got affected by antibiotics of different soil bacteria (table 2). E. coli growth was inhibited by soil organisms named $\mathrm{C} 1 \& \mathrm{C} 2$ and others like C3, C4, C5, C6 \& C7 have not shown any effect on growth of E.coli. Pathogen P. aeruginosa growth was inhibited by the effect of C2 (strain-1) whereas C1, C4, C6 $\& \mathrm{C} 7$ have not shown any effect. E. faecalis was affected by the antibiotics of $\mathrm{C} 4, \mathrm{C} 6 \&$ C7 \& remaining $\mathrm{C} 1, \mathrm{C} 2$ \& $\mathrm{C} 3$ have not shown the effect. These above results merely say that, the different pathogens have effected by different antibiotics secreted by different soil inhabiting free bacteria.

Table.1 Composition of nutrient agar medium \& nutrient broth medium

\begin{tabular}{|l|l|l|}
\hline \multirow{2}{*}{ Chemicals } & \multicolumn{2}{|c|}{ Composition g/1 } \\
\cline { 2 - 3 } & $\begin{array}{l}\text { Nutrient agar } \\
\text { medium }\end{array}$ & $\begin{array}{l}\text { Nutrient broth } \\
\text { medium }\end{array}$ \\
\hline Peptone & 10 & 10 \\
\hline Beef Extract & 3 & 3 \\
\hline Sodium Chloride & 5 & 5 \\
\hline Agar & 20 & -- \\
\hline Distilled Water & 1000 & 1000 \\
\hline $\mathrm{P}^{\mathrm{H}}$ & 7 & 7 \\
\hline
\end{tabular}


Table.2 Antibacterial activity of isolated soil bacteria strains against different pathogenic bacteria

\begin{tabular}{|l|l|l|l|l|l|l|l|l|l|}
\hline \multirow{2}{*}{ Names of pathogens } & \multicolumn{7}{|c|}{ Name of the isolated colonies } \\
\cline { 2 - 12 } & C1 & C2 & C3 & C4 & C5 & C6 & C7 & Control \\
\hline Eschereschia coli & + & + & - & - & - & - & - & + \\
\hline Enterococcus faecalis & - & - & - & + & - & + & + & + \\
\hline Stapylococcus aureus & - & + & + & - & + & - & - & + \\
\hline Pseudomonas aeruginosa & - & + & - & - & - & - & - & + \\
\hline
\end{tabular}

Table.3 Diameter of zone of inhibition of isolated colonies on respective pathogens

\begin{tabular}{|l|l|l|l|l|}
\hline Antibiotic producing bacteria & $\begin{array}{c}\text { Sources of soil } \\
\text { sample }\end{array}$ & \multicolumn{1}{|c|}{$\begin{array}{c}\text { Effects on } \\
\text { pathogen }\end{array}$} & $\begin{array}{c}\text { Zone of } \\
\text { inhibition }(\mathbf{c m})\end{array}$ & Control \\
\hline C1 & Rhizosphere soil & E. coli & 0.5 & 1.7 \\
\hline C2 (identified as P.aeruginosa) & Rhizosphere soil & $\begin{array}{l}\text { E. coli, } \\
\text { P. aeruginosa } \\
\text { S. aureus }\end{array}$ & $\begin{array}{l}1.2 \\
1.6\end{array}$ & 1.7 \\
& & S. aureus & 0.6 & 1.5 \\
\hline C3 & Rhizosphere soil & S. aurecalis & 2.0 & 1.6 \\
\hline C4 (identified as P.aeruginosa) & Forest soil & E. faecalis & 1.6 & 1.6 \\
\hline C5 & Pond soil & S. aureus & 1.5 \\
\hline C6 & Rhizosphere soil & E. faecalis & 1.5 & 1.5 \\
\hline C7 & Industrial soil & E. faecalis & 1.2 & \\
\hline
\end{tabular}

Fig.1 Colonies of $P$. aeruginosa grown on a) agar plate \& b) broth, with coloured pigments

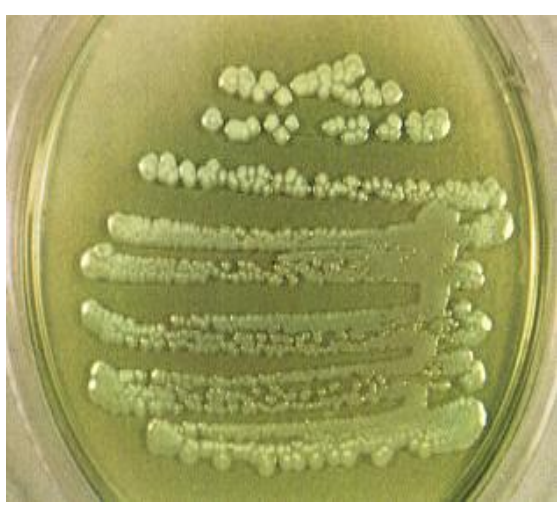

a

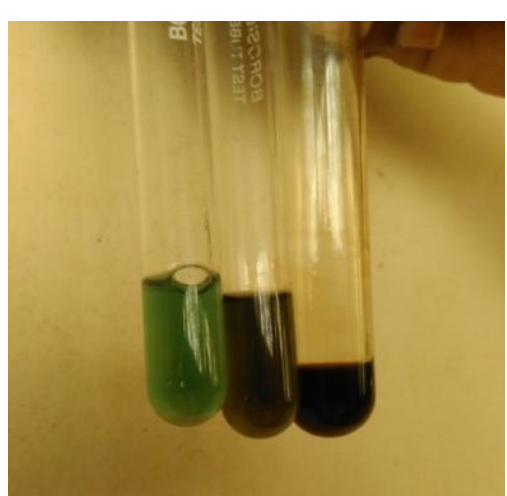

b 
Fig.2 Collected soil samples from different localities of Bidar

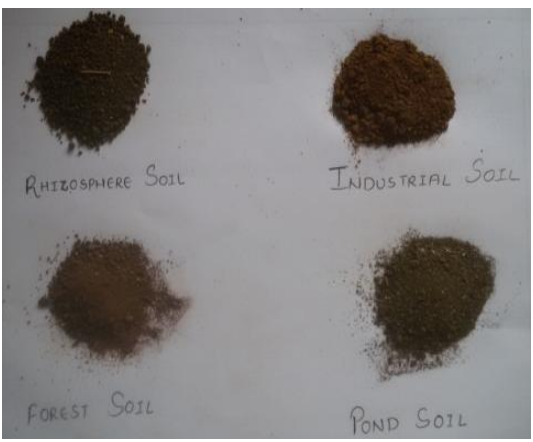

Fig.3 Bacterial colonies of different soil samples \& round marked selected species.
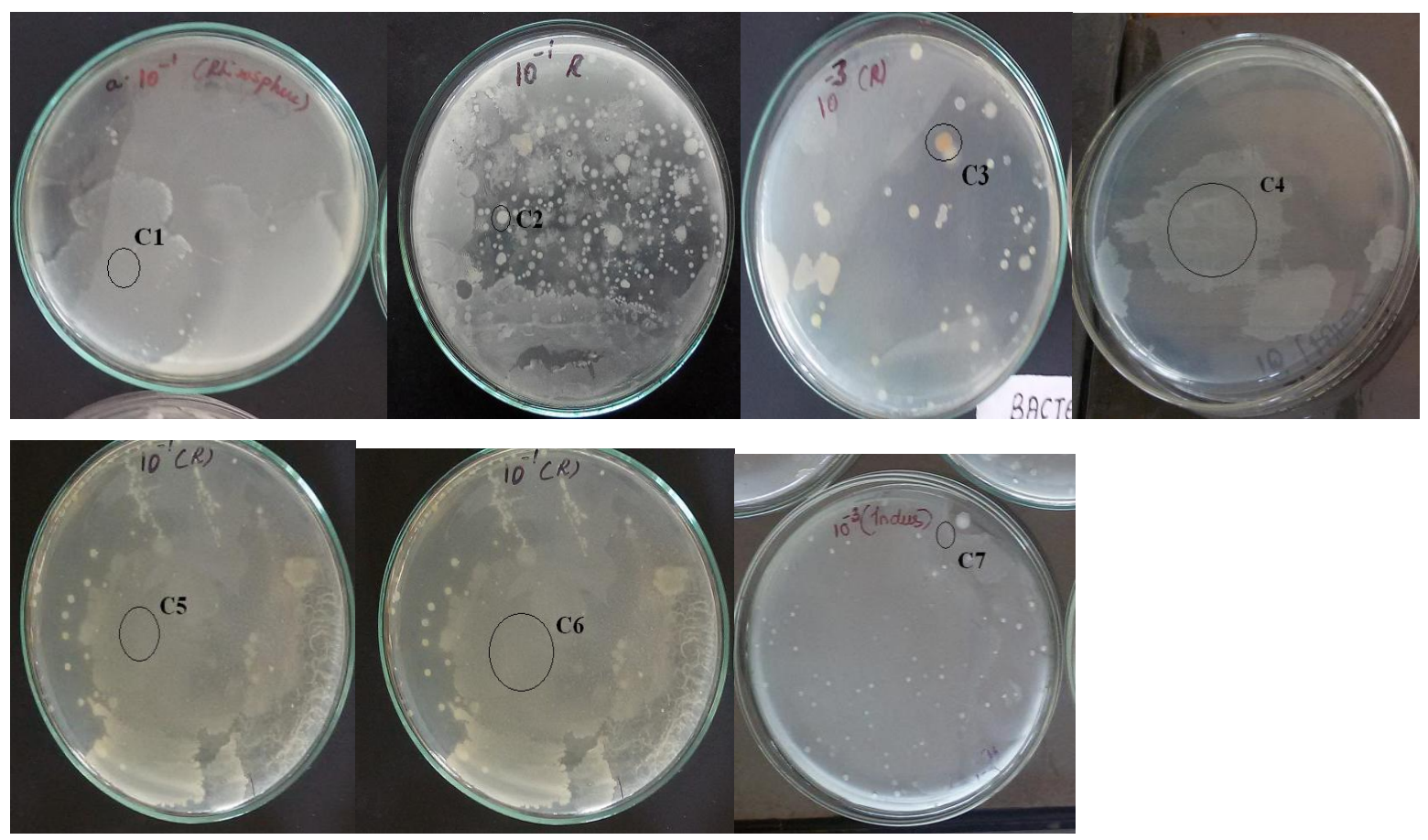

Fig.4 Antibacterial effect of isolated soil bacteria on cultures of a) E.coli, b) S.aureus, c) E.faecalis \& d) P. aeruginosa

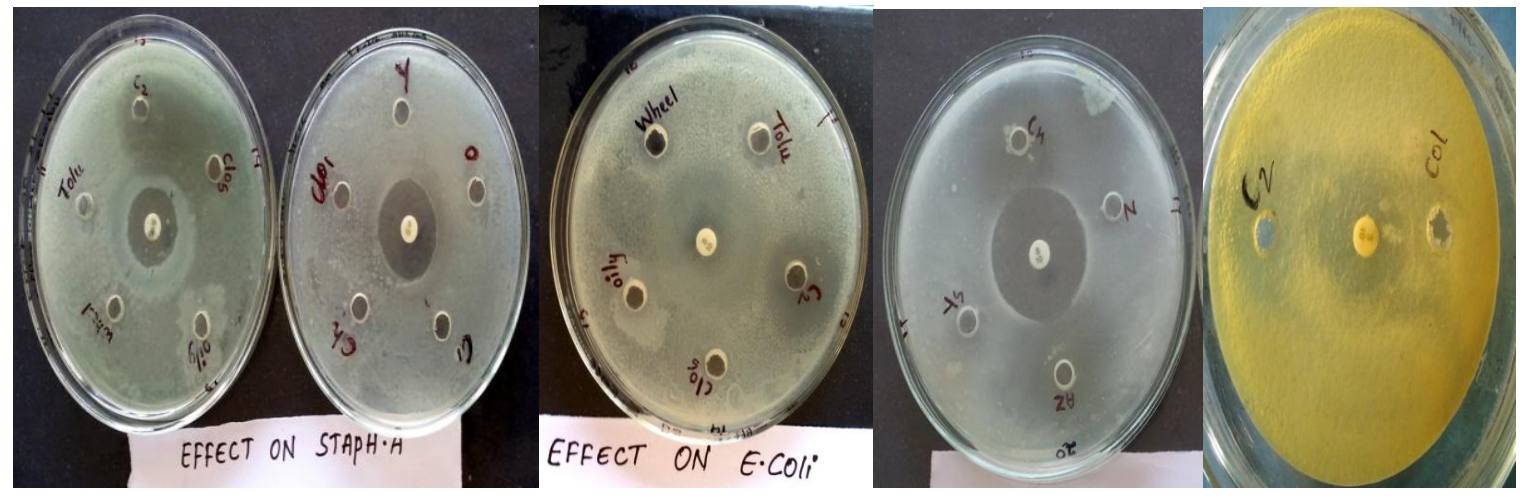


Fig.5a gDNA of the given sample C2

\section{1 .Aligned data of C2 Sample: (1230bp)}

GCTGGCAGTAATGCCTAGGAATCTGCCTGGTAGTGGGGGATAACGTCCGGAAACGGGCGCTAATACC GCATACGTCCTGAGGGAGAAAGTGGGGGATCTTCGGACCTCACGCTATCAGATGAGCCTAGGTCGGAT TAGCTAGTTGGTGGGGTAAAGGCCTACCAAGGCGACGATCCGTAACTGGTCTGAGAGGATGATCAGTC ACACTGGAACTGAGACACGGTCCAGACTCCTACGGGAGGCAGCAGTGGGGAATATTGGACAATGGGC GAAAGCCTGATCCAGCCATGCCGCGTGTGTGAAGAAGGTCTTCGGATTGTAAAGCACTTTAAGTTGGG AGGAAGGGCAGTAAGTTAATACCTTGCTGTTTTGACGTTACCAACAGAATAAGCACCGGCTAACTTCG TGCCAGCAGCCGCGGTAATACGAAGGGTGCAAGCGTTAATCGGAATTACTGGGCGTAAAGCGCGCGT AGGTGGTTCAGCAAGTTGGATGTGAAATCCCCGGGCTCAACCTGGGAACTGCATCCAAAACTACTGAG CTAGAGTACGGTAGAGGGTGGTGGAATTTCCTGTGTAGCGGTGAAATGCGTAGATATAGGAAGGAAC ACCAGTGGCGAAGGCGACCACCTGGACTGATACTGACACTGAGGTGCGAAAGCGTGGGGAGCAAACA GGATTAGATACCCTGGTAGTCCACGCCGTAAACGATGTCGACTAGCCGTTGGGATCCTTGAGATCTTA GTGGCGCAGCTAACGCGATAAGTCGACCGCCTGGGGAGTACGGCCGCAAGGTTAAAACTCAAATGAA TTGACGGGGGCCCGCACAAGCGGTGGAGCATGTGGTTTAATTCGAAGCAACGCGAAGAACCTTACCTG GCCTTGACATGCTGAGAACTTTCCAGAGATGGATTGGTGCCTTCGGGAACTCAGACACAGGTGCTGCA TGGCTGTCGTCAGCTCGTGTCGTGAGATGTTGGGTTAAGTCCCGTAACGAGCGCAACCCTTGTCCTTAG TTACCAGCACCTCGGGTGGGCACTCTAAGGAGACTGCCGGTGACAAACCGGAGGAAGGTGGGGATGA CGTCAAGTCATCATGGCCCTTACGGCCAGGGCTACACACGTGCTACAATGGTCGGTACAAAGGGTTGC CAAGCCGCGAGGTGGAGCTAATCCCATAAAACCGAATCAGTAGTCCGGATCGCAGTCTGCAACTCGAC TGCGTTGAAAAA

\section{Gel Photographs: \\ Genomic DNA:}

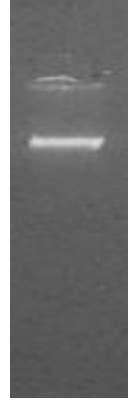

Fig.5b PCR Amplicon loaded on Agarose Gel

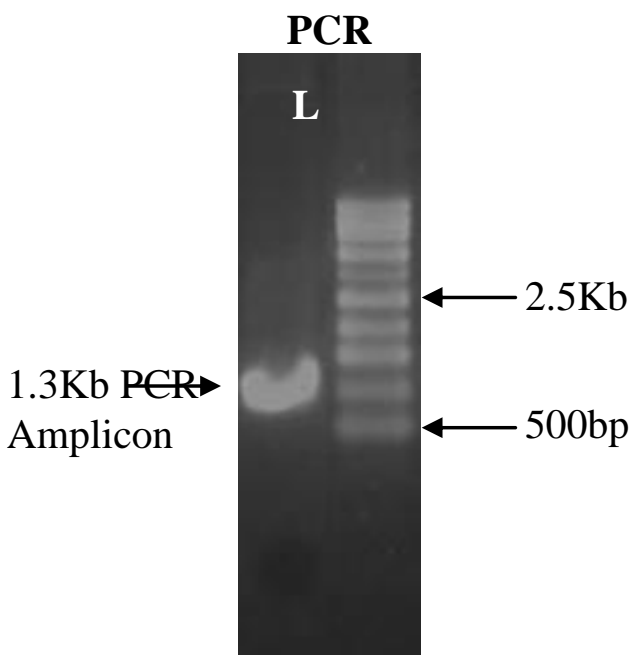

Lane Description: 1 - 16s rDNA PCR amplicon of C2 sample ( 1.3 Kb)L - 500bp DNA Ladder 
Fig.5c Genomic DNA Loaded on 1\% Agarose Gel

2. Aligned Data of C4>: (1242bp)

TGCAAGGGTAAATCGCCTAGGAATCTGCCTGGTAGTGGGGGATAACGTCCGGAAACGGGCGCT AATACCGCATACGTCCTGAGGGAGAAAGTGGGGGATCTTCGGACCTCACGCTATCAGATGAGCC TAGGTCGGATTAGCTAGTTGGTGGGGTAAAGGCCTACCAAGGCGACGATCCGTAACTGGTCTGA GAGGATGATCAGTCACACTGGAACTGAGACACGGTCCAGACTCCTACGGGAGGCAGCAGTGGG GAATATTGGACAATGGGCGAAAGCCTGATCCAGCCATGCCGCGTGTGTGAAGAAGGTCTTCGGA TTGTAAAGCACTTTAAGTTGGGAGGAAGGGCAGTAAGTTAATACCTTGCTGTTTTGACGTTACCA ACAGAATAAGCACCGGCTAACTTCGTGCCAGCAGCCGCGGTAATACGAAGGGTGCAAGCGTTAA TCGGAATTACTGGGCGTAAAGCGCGCGTAGGTGGTTCAGCAAGTTGGATGTGAAATCCCCGGGC TCAACCTGGGAACTGCATCCAAAACTACTGAGCTAGAGTACGGTAGAGGGTGGTGGAATTTCCT GTGTAGCGGTGAAATGCGTAGATATAGGAAGGAACACCAGTGGCGAAGGCGACCACCTGGACT GATACTGACACTGAGGTGCGAAAGCGTGGGGAGCAAACAGGATTAGATACCCTGGTAGTCCACG CCGTAAACGATGTCGACTAGCCGTTGGGATCCTTGAGATCTTAGTGGCGCAGCTAACGCGATAA GTCGACCGCCTGGGGAGTACGGCCGCAAGGTTAAAACTCAAATGAATTGACGGGGGCCCGCAC AAGCGGTGGAGCATGTGGTTTAATTCGAAGCAACGCGAAGAACCTTACCTGGCCTTGACATGCT GAGAACTTTCCAGAGATGGATTGGTGCCTTCGGGAACTCAGACACAGGTGCTGCATGGCTGTCG TCAGCTCGTGTCGTGAGATGTTGGGTTAAGTCCCGTAACGAGCGCAACCCTTGTCCTTAGTTAC CAGCACCTCGGGTGGGCACTCTAAGGAGACTGCCGGTGACAAACCGGAGGAAGGTGGGGATGA CGTCAAGTCATCATGGCCCTTACGGCCAGGGCTACACACGTGCTACAATGGTCGGTACAAAGGG TTGCCAAGCCGCGAGGTGGAGCTAATCCCATAAAACCGATCGTAGTCCGGATCGCAGTCTGCAA CTCGACTGCGTGAAGTCGGGAAAATTCCGG

Genomic DNA:

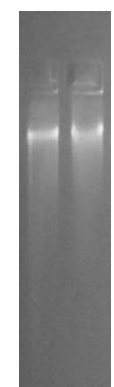

Fig.5d PCR Product loaded on 1\% Agarose Gel

PCR Product:

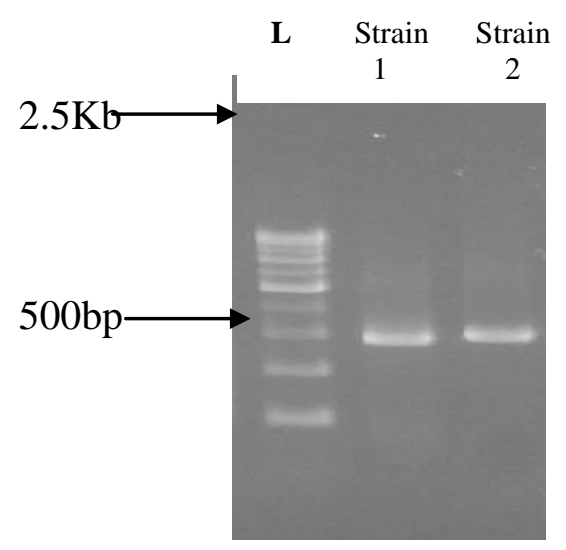

Lane Description 1.C4;

Lane Description: L - 500bp DNA Ladder 1 - C4 (1.3Kb) 2- C2(1.3Kb) 


\section{Phylogenetic tree of $\mathrm{C} 2 \& \mathrm{C} 4$ :}

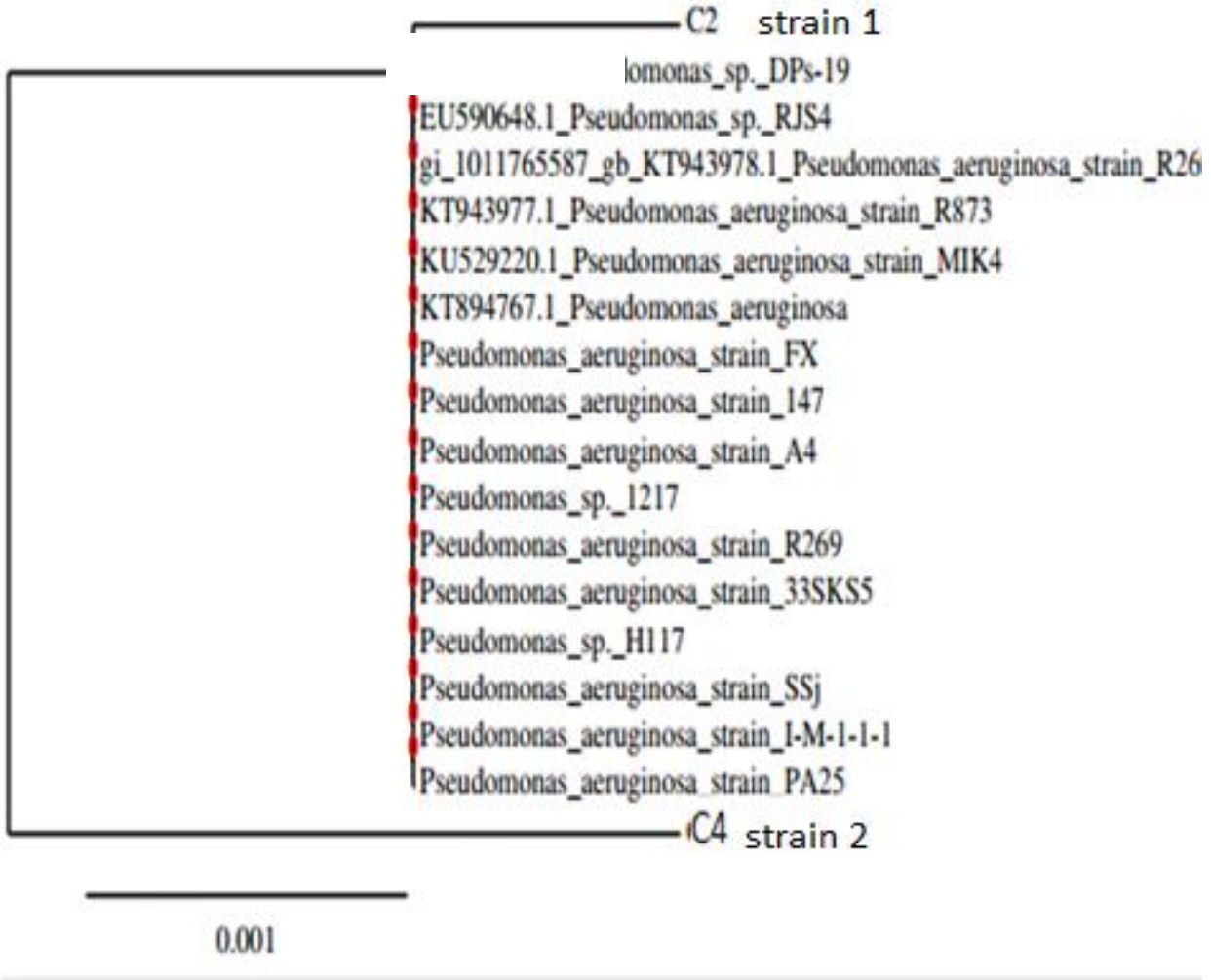

Fig.6 a, b, c \&d: Comparison of effect of antibiotics soil bacteria on test organisms
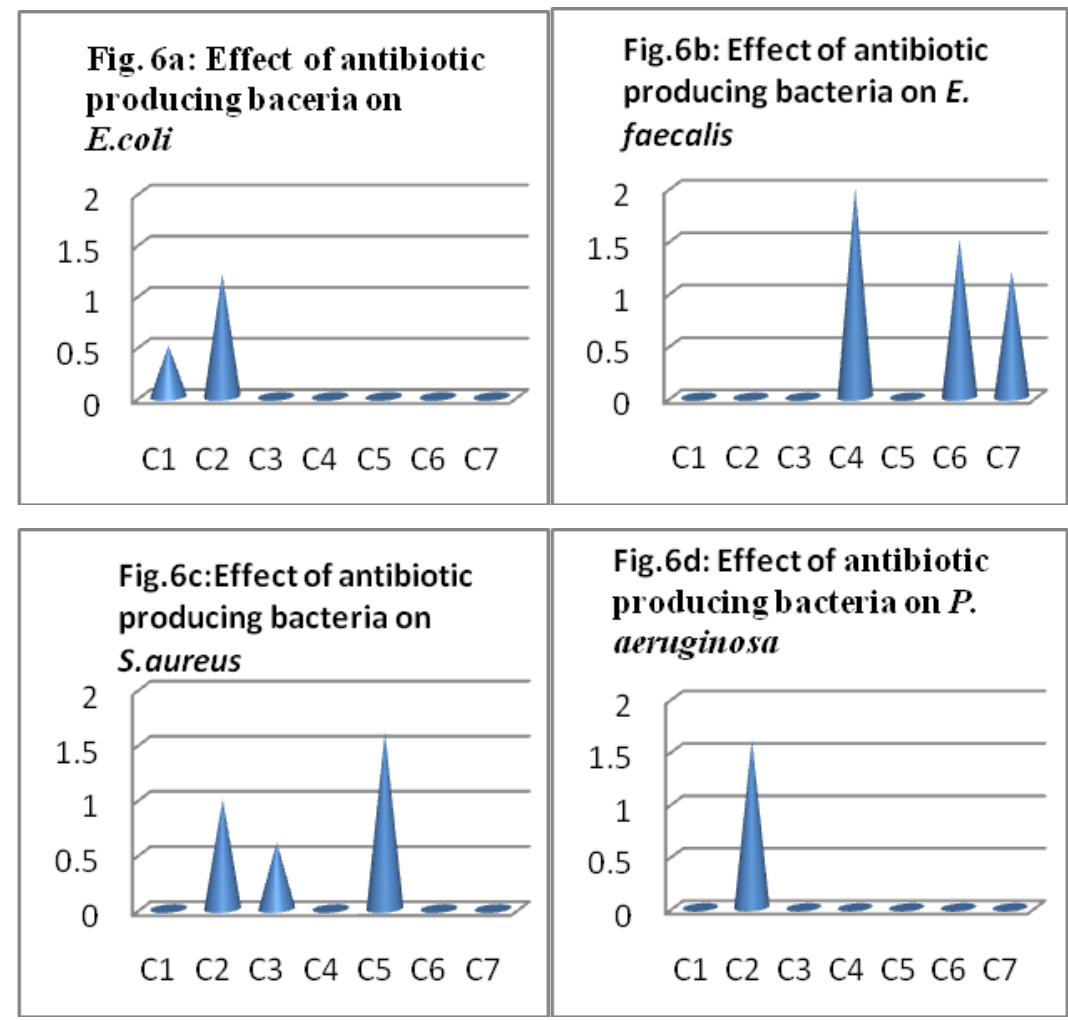
Fig.7 a,b,c\&d: Comparisons of effects of antibiotics of soil bacteria \& Streptomycin antibiotic on pathogens

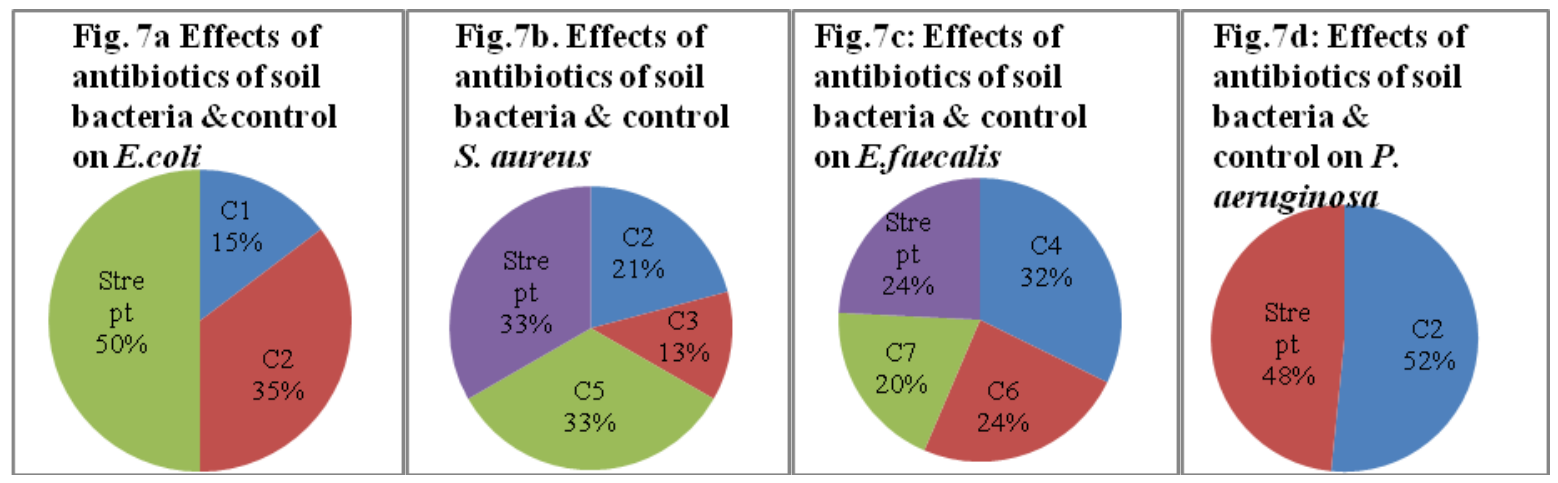

Further each of soil bacterial antibiotics shown varied degree of antibiotic effects on different pathogens (Table $3 \&$ Figs. 6a, b, c \& d). Soil bacteria $\mathrm{C} 2$ on $P$. aeruginosa, $\mathrm{C} 4 \& \mathrm{C} 6$ on $E$. faecalis and $\mathrm{C} 5$ on $S$. aureus have shown significant antibacterial effect as shown in figs.6a, b, c \& d. However, E. coli has found to be more resistant to all antibiotics of soil bacteria except $\mathrm{C} 1$ which also has less effect on E. coli, E. faecalis \& S. aureus pathogens were found more effective (susceptible) organisms by soil bacteria (Figs.9a,b,c \& d).

On E.coli the $\mathrm{C} 2$ is more effective than $\mathrm{C} 1$. On E. faecalis C6 is more effective than $\mathrm{C} 4$ followed by $\mathrm{C} 7$. On $S$. aureus, C5 is more effective than $\mathrm{C} 2$ followed by $\mathrm{C} 3$. On $P$. aeruginosa only $\mathrm{C} 2$ has shown growth inhibitory effect.

Antibiotics of soil bacteria $\mathrm{C} 1$ and $\mathrm{C} 2$ have less inhibition effect on growth of $E$. coli when compared to control (streptomycin antibiotic) fig.7a. Antibiotics of soil bacteria $\mathrm{C} 2$ and $\mathrm{C} 3$ have less inhibition effect and C5 has equal effect on growth of $S$. aureus, when compared to control (Streptomycin) fig.7b. Antibiotics of soil bacteria $\mathrm{C} 7$ has less inhibition effect and $\mathrm{C} 6$ has equal inhibition effect and $\mathrm{C} 4$ has more inhibition effect on growth of E. faecalis when compared to control (Streptomycin) fig.7c. Antibiotics of soil bacteria $\mathrm{C} 2$ have more inhibition effect on growth of $P$. aeruginosa when compared to control (Streptomycin) fig. $7 \mathrm{~d}$.

In conclusion, antibiotics are one of the important pillars of modern medicines (Ball et al., 2004), but either old antibiotics lose their efficiency or pathogens were becoming multidrug resistant, and hence they are necessarily replaced with new ones for many species of pathogenic bacteria (Hancock, 2007). From ancient times it is well understood that, natural products have a key role in the discovery in development of many antibiotics (Newman and Cragg, 2007). Majority of antibiotics so far isolated were produced from Streptomycetes, which are inhabitants of the soil (Srividya et al., 2008). Microorganisms that are able to produce efficient secondary metabolites have adverse chemical structure and biologically active are only by some species of genus bacillus (Stachelhaus et al., 1995). Pseudomonas species found predominant antibiotic producing bacteria from soil microorganisms. Majority of isolated bacteria were bacillus sps. and they have been found with different coloured pigments such as green, blue-green, brown, creamy white, pure white. Phenazines are heterocyclic compounds that are produced naturally by different bacterial species (Price-Whelan et al., 2006). Pyocyanin is water soluble blue green phenazine pigment produced in large quantities by $P$. 
aeruginosa. Pyocyanin is chemically $\mathrm{N}$ methyl-1-hydroxyphenazine has antibiotic activity against wide variety of microorganisms. Out of seven antibiotic producing bacteria $\mathrm{C} 1$ antibiotic has inhibition effect on growth of E. coli; C2 ( $P$. aeruginosa Strain-1) antibiotic has inhibition effect on growth of E. coli, $P$. aeruginosa \& S. aureus; C3 antibiotic has inhibition effect on growth of $S$. aureus; C4 $(P$. aeruginosa Strain-2) antibiotic has inhibition effect on growth of E. faecalis; C5 antibiotic has inhibition effect on growth of $S$.aureus; C6 antibiotic has inhibition effect on growth of E. faecalis; $\mathrm{C} 7$ antibiotic has inhibition effect on growth of E. faecalis. C2 \& C4 colonies were detected as $P$. aeruginosa with two strains. Each of soil bacterial antibiotics shown varied degree of antibiotic effects on different pathogens. C4 has highest inhibitory effect of the growth of E. faecalis; followed by C5 on S. aureus and $\mathrm{C} 2$ on $P$. aeruginosa. The antibiotic of some selected soil bacteria and commercial antibiotics have almost similar \& equivalent affect on four studied pathogens.

\section{References}

Atlas, R.M. \& Bartha, R. 1998. Fundamentals and applications. In: Microbialecology. $4^{\text {th }}$ ed. New York: Benjamin/Cummings Science publishing. 174-217.

Brock, T.D. \& Madigan, M.T. 1991. Biology of Microorganism. $6^{\text {th }}$ edn. Prentice-Hall International Inc., USA.

Ball, A.P., Bartlett, J.G., Craig, W.A., Drusana, G.L., Felmingham, D., Garau, J.A., Klugman, K.P., Low, D.E., Mandell,
L.A., Rubinstein, E. \& Tillotson, G.S. 2004. Future trends in antimicrobial chemotherapy: Expert opinion on the $43^{\text {rd }}$ ICAAC. J. Chemother., 16: 419-436.

Cordell, G.A., Farnsworth, N.R., Beecher, C.W., Soejarta, D.D., Kinghorm, A.D., Pezzuto, J.M., Wall, M.E., Wani, M.C., Cobb, R.O., Neil, M.J.R., Tait, M., Harris, T.J.R. 1994. Novel strategies for the discovery of plant derived anticancer agents. 63-83.

Hancock, R.E.W. 2007. The end of an Era? Nat. Rev. Drug. Discov., 6: 28.

Newman, D.J. \& Cragg, G.M. 2007. Natural products as sources of new drugs over the last 25yrs. J. Nat. Prod., 70: 461-477.

Price-Whelan, A., Dietrich, L.E.P. \& Newman, D.K. 2006. Rethinking 'secondary' metabolism: physiological roles for phenazine antibiotics. Nature Chem. Biol., 2: 71-78.

Sandhya, M.V.S., Ramyakrishna, E., Divya, P., Pawankumar, A., Karthik, R., Yazein, E., \& Sandeepta, B. 2015. "Isolation of antibiotic producing bacteria from soil." Int. J. Appl. Biol. Pharmaceutical Technol., 6. issue 1.

Srividhya, A.R., Sarita, G.S. \& Suresh, B. 2008. "Study of the soil isolates for antimicrobial activity." Indian J. Pharm, Sci., 70(6): 812-815.

Stachelhaus, T., Schneider, A. \& Marahiel, M.A. 1995. Rational design of peptide antibiotics by targeted replacement of bacterial and fungal domince. Sci., 269: 69-72.

Vineeta, S., Vandana, P., Jaspreet, B. \& Tripathi, C.K.M. 2009. Antimicrobial activities of microbial strains isolated from soil of stressed ecological niches of Eastern Uttar Pradesh, India, 47: 298-303.

\section{How to cite this article:}

Vijaykumar Biradar, S. Ashwini, Pooja Lachuriye, Sadia Fatima and Awase Syed. 2016. Isolation of Soil Bacteria for Potential Production of Antibiotics and their Inhibitory Effect on Growth of Pathogens. Int.J.Curr.Microbiol.App.Sci. 5(8): 514-524.

doi: http://dx.doi.org/10.20546/ijcmas.2016.508.055 